\title{
Time-dependent variations in urine volume and serum creatinine levels during post-operative hospital stay period after renal transplantation: experience in a tertiary care hospital of Bangladesh
}

\author{
Khoda MME ${ }^{\mathrm{a}}$, Rahim MA ${ }^{\mathrm{b}}$, Shimu IJ ${ }^{\mathrm{c}}$, Hossain $\mathrm{MG}^{\mathrm{d}}$, Sharif A ${ }^{\mathrm{e}}$, Mansur MA ${ }^{\mathrm{f}}$
}

\begin{abstract}
Background: Kidney transplantation is the preferred treatment for end stage kidney disease (ESKD). Early post kidney transplant urine volume may correlate with favorable allograft survival. The aim of the present study was to examine the potential changes in urine volume with serum creatinine during post-operative hospital stay period after renal transplantation.

Methods: We retrospectively reviewed the medical records of patients who had undergone kidney transplantation at Bangladesh Institute of Research and Rehabilitation of Diabetes, Endocrine and Metabolic Disorders (BIRDEM) General Hospital, Dhaka, Bangladesh between November 2004 and February 2019. Total patients were 133. Twenty four hour urine volume and serum creatinine levels were measured on day 1, day 5 and day 10 after operation. Correlation was performed by using Pearson correlation test.
\end{abstract}

Results: The mean age of the renal allograft recipients was 36.7 \pm 10.3 years with male to female ratio of 2.7:1. The mean 24 hours urine volume on Day 1, Day 5 and Day 10 were $8990 \pm 5377 \mathrm{ml}, 4860 \pm 2074 \mathrm{ml}$ and $4485 \pm 1722 \mathrm{ml}$ respectively and serum creatinine levels were $3.5 \pm 1.5 \mathrm{mg} / \mathrm{dl}, 1.6 \pm 1.2 \mathrm{mg} / \mathrm{dl}$ and $1.5 \pm 1.3 \mathrm{mg} / \mathrm{dl}$ respectively. Negative correlation were found between the Day 1, Day 5 and Day 10 serum creatinine and the urine volume $(\mathrm{r}=0.366,0.507,0.365$ respectively) with significant $p$ values $(<0.01)$ in each group.

Conclusion: Although urine volume showed considerable variation in early post renal transplantation, it stabilized by the course of time, which was also negatively correlated with the serum creatinine levels.

Key word: kidney transplant recipient, urine volume, serum creatinine.

(BIRDEM Med J 2020; 10(3): 149-151)

\section{Author information}

a. Mohammad Mehfuz E Khoda, Junior Consultant, Kidney Transplant Unit, BADAS \& Nephrology and Dialysis Unit, BIRDEM General Hospital, Dhaka, Bangladesh.

b. Muhammad Abdur Rahim, Associate Professor, Department of Nephrology, BIRDEM General Hospital, Dhaka, Bangladesh.

c. Ishrat Jahan Shimu, Assistant Professor, Department of Cardiology, National Institute of Cardiovascular Diseases, Dhaka, Bangladesh.

d. Md. Golzar Hossain, Transplant Coordinator, Kidney Transplant Unit, BADAS \& Senior Medical Officer, Nephrology and Dialysis Unit, BIRDEM General Hospital, Dhaka, Bangladesh.

e. Ahmed Sharif, Senior Medical Officer, Nephrology and Dialysis Unit, BIRDEM General Hospital, Dhaka, Bangladesh.

f. Md. Abul Mansur, Director, Kidney Transplant Unit, BADAS \& Professor, Nephrology and Dialysis Unit, BIRDEM General Hospital, Dhaka, Bangladesh.

Address of Correspondence: Mohammad Mehfuz E Khoda, Junior Consultant, Kidney Transplant Unit, BADAS \& Nephrology and Dialysis Unit, BIRDEM General Hospital, Dhaka, Bangladesh, Email:mehfuzek@yahoo.com

Received: July 19, 2019

Accepted: June 30, 2020

\section{Introduction}

When kidneys fail, treatment is needed to replace the work of kidneys. There are two types of treatment for kidney failure- dialysis or transplant. In recent years, several studies have documented that early ( $1^{\text {st }}$ week) graft function post-kidney transplantation impacts long term graft survival. ${ }^{1}$ Immediately after kidney transplantation diuresis begins. ${ }^{2}$ Although controversial, the early post kidney transplant urine volume may correlate with favorable short and long term graft survivals. ${ }^{2}$ High urine volume during the first posttransplant days is a useful parameter to predict graft outcome. ${ }^{3,4}$ The aim of the present study was to examine potential variation in urine volume and serum creatinine levels immediately after transplantation and during hospital course after kidney transplantation and also elucidate possible correlations between urine volume and serum creatinine levels during this period. 


\section{Methods}

A cross-sectional retrospective study was conducted in 133 live related kidney transplant recipient at Bangladesh Institute of Research and Rehabilitation of Diabetes, Endocrine and Metabolic Disorders (BIRDEM) General Hospital, Dhaka, Bangladesh between November 2004 to February 2019. Twenty four hours urine volume and serum creatinine levels were measured on day 1, day 5 and day 10 after operation. All patient received Methyl prednisolone followed by oral prednisolone, Cyclosporine or tecrolimus and mycophenolate mofetil as immunosuppressive agents. Following transplantation, fluid replacement was started with normal or hypotonic saline based on the serum electrolyte status and urine volume. Statistical analysis was performed by SPSS version 22 and results were expressed in mean value \pm standard deviation and Pearson correlation test. The $\mathrm{p}$ value for significance was set at 0.05 .

\section{Results}

Total 133 kidney transplant recipient were included in this study, among them 97 were male and 36 were female with male to female ratio of $2.7: 1$. The mean age of the renal allograft recipients was $36.7 \pm 10.3$ years and most patient were within age group of 31-40 year. (Figure 1) The mean 24 hours urine volume and serum creatinine on Day 1 were $8990 \pm 5377 \mathrm{ml}$ and $3.5 \pm 1.5 \mathrm{mg} / \mathrm{dl}$ respectively, on Day 5 were $4860 \pm 2074 \mathrm{ml}$ and1.6 \pm 1.2 $\mathrm{mg} / \mathrm{dl}$ respectively and on Day 10 were $4485 \pm 1722 \mathrm{ml}$ and $1.5 \pm 1.3 \mathrm{mg} / \mathrm{dl}$ respectively. Negative correlation were found between Day 1, Day 5 and Day 10 serum creatinine and the urine volume $(r=0.366,0.507,0.365$ respectively) with significant $\mathrm{p}$ values $(<0.01)$ in each group. (Figures 2, 3 and 4)

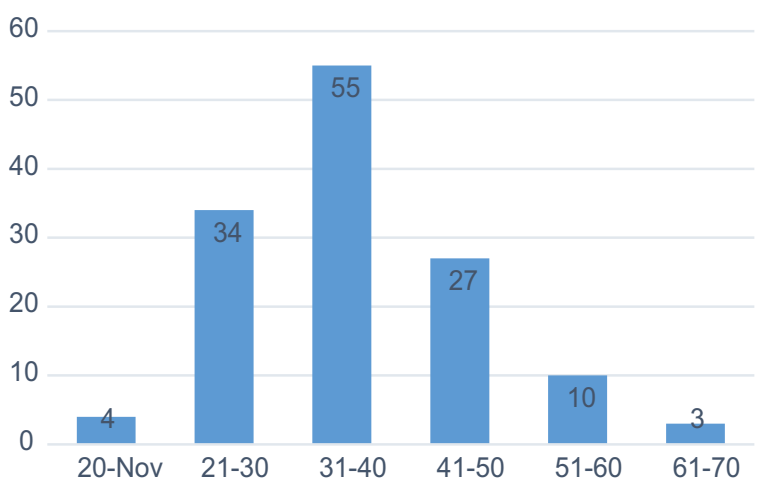

Figure 1 Distribution of age of recipients $(\mathrm{N}=133)$

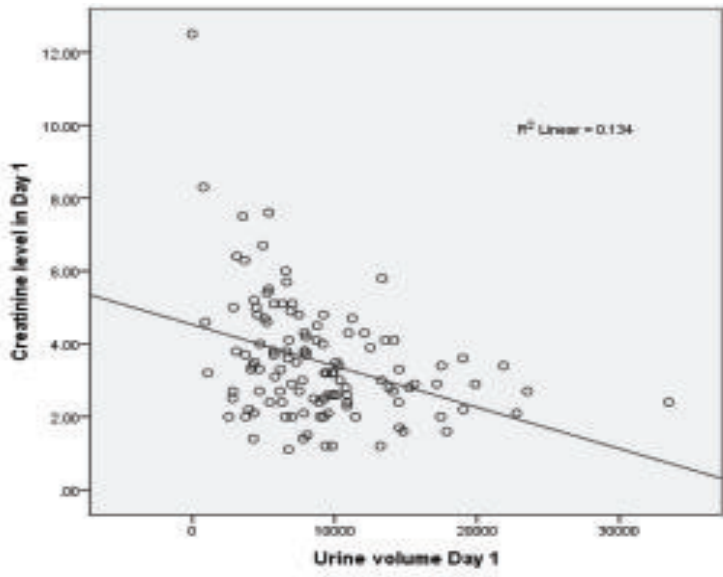

Figure 2 Correlation of serum creatinine with urine volume in Day $1(\mathrm{~N}=133)$

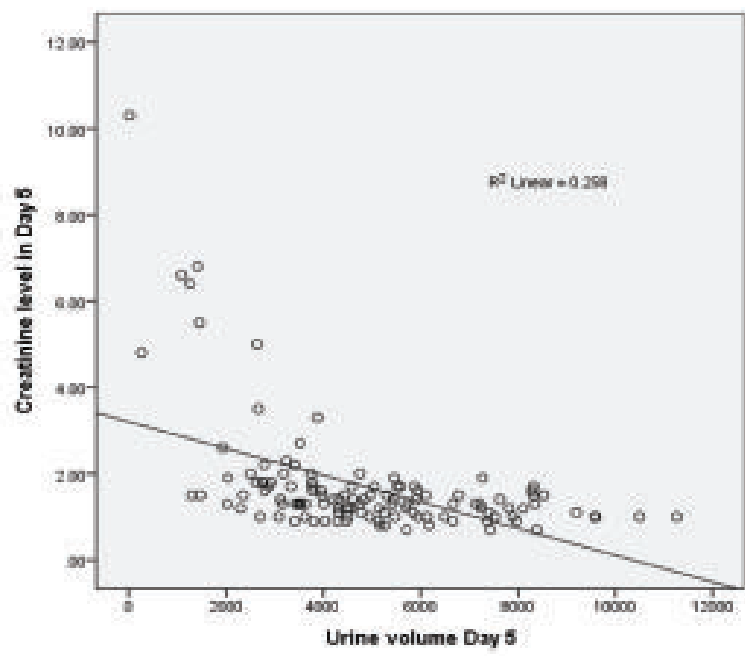

Figure 3 Correlation of serum creatinine with urine volume in Day $5(\mathrm{~N}=133)$

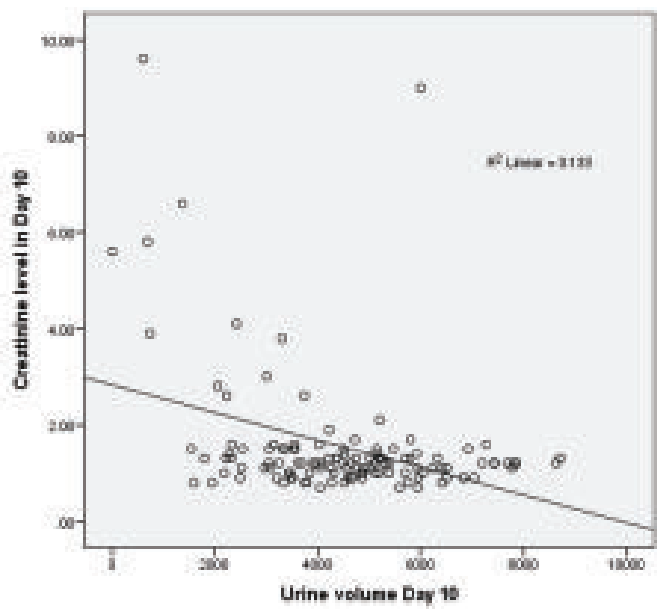

Figure 4 Correlation of serum creatinine with urine volume in Day $10(\mathrm{~N}=133)$ 


\section{Discussion}

This retrospective study was performed in 133 posttransplant recipients from November 2004 to February 2019. Among the patients, 97 were male and 36 were female with male to female ratio of 2.7: 1 . The mean ages of the study subject was $36.7 \pm 10.3$ years and most of the patients were within 21 to 60 years. In a previous study showed the almost similar mean age and male to female ratio. ${ }^{2}$ In urine volume, the results of this study showed gradual decreased in urine volume after kidney transplant operation from day 1 to day 5 and then stabilized within day10. It had been shown that the urine volume is usually high within the first 24 to 48 hours after transplantation. In some studies showed urine volume after post-operative period of kidney transplantation were $10.06 \pm 5.89$ liter followed by $5.45 \pm 3.05$ liter which were almost similar to this study. ${ }^{4-6}$

The outcome for kidney transplant recipients has markedly improved since it was started. Day to day variation in kidney function, as expressed by serum levels of creatinine could be related to the 24 hours urine volume. We found a negative correlation between serum creatinine and 24 hours urine volume during day 1, day 5 and day 10 after kidney transplantation. But in a previous study, it is demonstrated a direct relation between serum creatinine and diuresis volume after kidney transplantation. ${ }^{4}$

\section{Limitations and recommendations}

As sample size was small in a single center, the finding derived from study cannot be generalized to reference population. So for further recommendation, multicenter study with large sample size is emphasized.

\section{Conclusion}

Although urine volume showed considerable variation in early post renal transplantation, it stabilized by the course of time, which was also negatively correlated with the serum creatinine levels. Moreover one may conclude these, in stable patient the final urine volume was related to the early graft function.

Conflicts of interest: Nothing to declare.

\section{References}

1. Moore J, Ramakrishna S, Tan K, Cockwell P, Eardley K, Little $\mathrm{MA}$, et al. Identification of the optimal donor quality scoring system and measure of early renal function in kidney transplantation. Transplantation 2009 Feb 27;87(4):578-586

2. Khosroshahi HT, Oskui R, Shoja MM, Tubbs RS, Ardalan MR. Time-dependent variations in urine output after renal transplantation. Transplantation Proceedings 2007; 39: 93233.

3. Ardalan MR, Argani H, Mortazavi M, Tayebi H, Abedi AS, Toluey M. More urine is better after renal transplantation. Transplant Proc 2003 Nov; 35 (7): 2612-13.

4. Matteucci E, Carmellini M, Bertoni C, Boldrini E, Mosca F, Giampietro O. Urinary excretion rates of multiple renal indicators after kidney transplantation: clinical significance for early graft outcome. Renal Fail 1998; 20 (2): 325-30.

5. Dawidson I, Berglin E, Brynger H, Reisch J. Intravascular volumes and colloid dynamics in relation to fluid management in living related kidney donors and recipients. Crit Care Med 1987 Jul; 15(7):631-36.

6. Hatch DA, Barry JM, Norman DJ. A randomized study of intravenous fluid replacement following living-donor renal transplantation. Transplantation 1985 Dec; 40(6):648-51. 